\title{
FATORES QUÍMICOS E FÍSICOS QUE AFETAM A CONTAMINAÇÃO POR CHUMBO E COBRE EM ÁGUA POTÁVEL: UMA ABORDAGEM PARA O ESTUDO DE CASO EM QUÍMICA ANALÍTICA
}

Tahuana L. B. Grigoletto, Bruno H. C. Fuzari, Adalgisa R. Andrade e Maria Lúcia A. M. Campos*

Departamento de Química, Faculdade de Filosofia Ciências e Letras de Ribeirão Preto, Universidade de São Paulo, Av. Bandeirantes, 3900, 14040-901 Ribeirão Preto - SP, Brasil

Raquel Fernanda Gerlach

Departamento de Morfologia Estomatologia e Fisiologia, Faculdade de Odontologia de Ribeirão Preto, Universidade de São Paulo, Av. do Café, s/n, 14040-904 Ribeirão Preto - SP , Brasil

José Eduardo Tanus dos Santos

Departamento de Farmacologia, Faculdade de Medicina de Ribeirão Preto, Universidade de São Paulo, Av Bandeirantes, 3900 , 14049-900 Ribeirão Preto - SP, Brasil

Recebido em 16/5/12; aceito em 3/7/12; publicado na web em 17/9/12

\begin{abstract}
CHEMICAL AND PHYSICAL FACTORS INFLUENCING LEAD AND COPPER CONTAMINATION IN DRINKING WATER: APPROACH FOR A CASE STUDY IN ANALYTICAL CHEMISTRY. Lead and copper concentrations in drinking water increase considerably on going from municipality reservoirs to the households sampled in Ribeirão Preto (SP-Brazil). Flushing of only 3 liters of water reduced metal concentrations by more than $50 \%$. Relatively small changes in water $\mathrm{pH}$ rapidly affected corrosion processes in lead pipes, while water hardness appeared to have a long-term effect. This approach aims to encourage University teachers to use its content as a case study in disciplines of Instrumental Analytical Chemistry and consequently increase knowledge about drinking water contamination in locations where no public monitoring of trace metals is in place.
\end{abstract}

Keywords: trace metals; stripping voltammetry; lead pipes.

\section{INTRODUÇÃO}

O chumbo encontrado no meio ambiente pode ser absorvido pelo organismo humano pela inalação de poeira, e pela ingestão de água e alimentos contaminados. As crianças são particularmente mais sensíveis à exposição ao chumbo do que os adultos, pois seus órgãos e sistemas ainda estão em desenvolvimento. ${ }^{1}$

Em 1979, Needleman e colaboradores ${ }^{2}$ demonstraram que a dentina de dentes decíduos (de leite) atua como tecido marcador da exposição a chumbo, e comprovaram que a exposição de chumbo na infância leva à diminuição de QI, inabilidades de fala e atenção, e distúrbios no desenvolvimento psíquico da criança. Os trabalhos que provaram que a intoxicação por chumbo interfere irreversivelmente em funções importantíssimas para o desenvolvimento psicomotor de crianças, embora aceitos no meio científico, trouxeram como consequência a perseguição do americano Herbert Needleman, pois este associou a contaminação das crianças com indústrias que usavam chumbo nos Estados Unidos. ${ }^{3}$ Esse episódio acabou provocando um grande movimento das entidades de direitos civis, que resultou na implementação de programas para detecção de crianças contaminadas e prevenção da exposição a chumbo de todas as formas. Foram criadas leis proibindo o uso de chumbo na gasolina, em tintas, em soldas de alimentos enlatados, e estabelecendo a substituição dos encanamentos de água e o monitoramento das concentrações de chumbo na água potável.

No trabalho de De Capitani e colaboradores ${ }^{4}$ foram apresentadas diversas fontes de exposição humana ao chumbo no Brasil incluindo encanamentos de chumbo, que podem ser uma importante fonte de contaminação. No Brasil, não há políticas públicas voltadas para o controle sistemático de chumbo na água das casas, sendo que casas com encanamentos de mais de 40 ou 50 anos não são raras em cidades

*e-mail: 1campos@ffclrp.usp.br mais antigas, principalmente entre populações de baixa renda. Os processos de tratamento que usam o cloro como agente desinfetante na água podem promover a solubilização de produtos de corrosão de chumbo nos encanamentos, como o $\mathrm{PbO}_{2} .{ }^{5}$

O Centro de Controle de Doenças dos Estados Unidos ${ }^{6}$ e a Agência de Proteção Ambiental dos Estados Unidos ${ }^{7}$ recomendam deixar a água que ficou estagnada por muitas horas no encanamento escoar durante $60 \mathrm{~s}$ antes do uso, como uma prática que reduz a exposição ao chumbo pela água de beber. Porém, medidas como essa, só se tornam verdadeiramente eficazes no caso de casas térreas, pois, no caso de apartamentos, esse tempo de escoamento pode ser maior. ${ }^{8}$

A Organização Mundial da Saúde sugere $10 \mu \mathrm{g} \mathrm{L} \mathrm{L}^{-1}$ (48,3 nmol $\left.\mathrm{L}^{-1}\right)$ como limite tolerável de chumbo em água, sendo este valor também adotado no Brasil (Portaria 2914/2011, Ministério da Saúde). No caso do cobre, o limite tolerável pela portaria é de 2,0 $\mathrm{mg} \mathrm{L}^{-1}$. As fontes principais de contaminação por cobre estão centradas nos processos industriais e atividades agrícolas. ${ }^{9}$ Porém, há também canos de cobre, ou soldas de chumbo e cobre, que neste caso funciona como uma célula eletroquímica espontânea (galvânica), dada a diferença no potencial padrão de redução destes metais $\left(\mathrm{E}^{0} \mathrm{~Pb}^{2+} / \mathrm{Pb}=-0,13 \mathrm{~V}\right.$ e $\left.\mathrm{E}^{0} \mathrm{Cu}^{2+} / \mathrm{Cu}=+0,34 \mathrm{~V}\right)$, elevando, assim, a dissolução de chumbo. ${ }^{10}$

A Agência de Proteção Ambiental dos Estados Unidos monitora de forma sistemática as concentrações de chumbo e cobre na água potável das residências, e no caso da concentração de chumbo estar acima de $15 \mu \mathrm{g} \mathrm{L}^{-1}\left(72,4 \mathrm{nmol} \mathrm{L} \mathrm{L}^{-1}\right)$ e de cobre acima de $1,3 \mathrm{mg} \mathrm{L}^{-1}$ $\left(20 \mu \mathrm{mol} \mathrm{L}{ }^{-1}\right)$ em mais de $10 \%$ das casas monitoradas, níveis de ação devem ser tomados. Esses níveis de ação foram estabelecidos em 1991 e são chamados de Lead and Copper Rule. As concentrações de ambos os metais são monitoradas de forma sistemática pelo poder público, sendo que a periodicidade da amostragem pode variar de meses até anos, dependendo do percentual de casas com elevadas 
concentrações dos metais. Medidas a curto prazo são o controle de corrosão, o monitoramento de mais parâmetros químicos na água e a orientação/educação da população. A longo prazo, os canos podem ser substituídos.

Na cidade de Ribeirão Preto (SP) 247 crianças de 4-6 anos tiveram a concentração de chumbo no esmalte dentário avaliada, sendo revelado que $12 \%$ delas apresentaram concentrações de chumbo tão elevadas quanto crianças residentes em uma região notoriamente contaminada por chumbo, próxima de uma fábrica de bateria na cidade de Bauru (SP). ${ }^{11}$ Considerando a repercussão dos trabalhos de Almeida e colaboradore ${ }^{11-13}$ nos meios de comunicação na cidade de Ribeirão Preto, observamos que este poderia ser um ótimo estudo de caso para compor disciplinas de Química Analítica Instrumental dos cursos de Química.

Sá e colaboradores ${ }^{14}$ apontaram a grande carência de aplicação de métodos de estudo de caso no curso de Química. Os autores discutem a importância desse método para que os alunos entrem em contato com problemas reais e se tornem responsáveis pela promoção do seu próprio aprendizado. A proposta de investigação da contaminação da água potável com chumbo e cobre em casas da comunidade teria a característica de agregar o conhecimento analítico aos aspectos sociais, econômicos, éticos e ambientais, como preconiza um bom estudo de caso.

Enquanto os livros didáticos de Análise Instrumental ${ }^{15}$ tendem a abordar os fundamentos teóricos de diversas técnicas sem abranger aspectos experimentais, os artigos científicos envolvendo técnicas analíticas buscam o estado da arte, visando um público especializado. Desta forma, é importante aumentar o leque de opções de experimentos viáveis para alunos de graduação a fim de permitir que docentes e alunos ampliem a aplicação de técnicas instrumentais durante a formação do aluno.

A voltametria de redissolução é uma técnica analítica com amplas aplicações tanto na investigação científica qualitativa, como na determinação quantitativa de uma grande variedade de espécies químicas. Desta forma, entendemos que esse tema deve fazer parte da formação dos Químicos.

Um dos objetivos deste trabalho foi fornecer subsídios teóricos e experimentais para a aplicação da voltametria de redissolução em estudos de casos no ensino Química Analítica Instrumental. Além disso, o estudo de caso aqui apresentado visa avaliar alguns parâmetros físicos e químicos que atuam na contaminação por cobre e chumbo na água potável. Este estudo tem um importante cunho social e pode servir de base para a investigação da contaminação da água potável em outras cidades brasileiras.

\section{Fundamentos da voltametria de redissolução}

A voltametria é definida como uma técnica que emprega eletrodo de trabalho polarizável (líquido ou sólido), ao qual são aplicados potenciais crescentes (no sentido positivo ou negativo), medindo-se a corrente gerada na célula eletrolítica devido ao transporte de massa por difusão e/ou convecção. Já, o termo polarografia, restringe-se apenas ao uso especifico do eletrodo gotejante de mercúrio. ${ }^{15}$

\section{Voltametria de redissolução anódica (VRA)}

O termo 'voltametria de redissolução anódica' (VRA) é utilizado quando a espécie de interesse é acumulada no eletrodo de trabalho durante a aplicação de um potencial mais negativo do que o potencial de pico correspondente à oxidação da espécie de interesse. No caso de uma espécie metálica $\left(\mathrm{M}^{\mathrm{n}+}\right)$ e eletrodo de mercúrio de gota pendente, há formação de amálgama durante o período de pré-concentração (1), pois o metal é reduzido na gota de mercúrio.

$$
\mathrm{M}^{\mathrm{n}+}+\mathrm{ne}^{-}+\mathrm{Hg} \rightarrow \mathrm{M}(\mathrm{Hg})
$$

Após o processo de deposição, que geralmente é realizado sob agitação, há uma pausa por cerca de 10 a 30 s para homogeneização do metal, antes da varredura de potencial para valores menos negativos. Assim ocorre a reoxidação do metal depositado sobre a gota de mercúrio (2), produzindo uma corrente anódica proporcional à concentração do metal na amostra.

$$
\mathrm{M}(\mathrm{Hg}) \rightarrow \mathrm{M}^{\mathrm{n}+}+\mathrm{ne}^{-}+\mathrm{Hg}
$$

A repetição do mesmo procedimento em nova gota de mercúrio após adição de padrões permite a determinação da concentração da espécie de interesse em solução.

Quando a reação eletroquímica é reversível ou parcialmente reversível, a aplicação de pulsos durante a varredura de potencial faz com que a espécie de interesse seja oxidada e reduzida muitas vezes antes de atingir o potencial de pico, elevando assim a corrente faradaica produzida. ${ }^{16}$

Na VRA utilizando o eletrodo de mercúrio, a formação de amalgama é obrigatória, restringindo o método para elementos solúveis nesse metal. Outra limitação importante é a própria oxidação do mercúrio em potenciais próximos de $0 \mathrm{~V}$ e a redução do hidrogênio da água gerando $\mathrm{H}_{2}$, em cerca de $-1,5 \mathrm{~V}$, restringindo o uso da técnica aos elementos cujo potencial de redução/oxidação está dentro desse intervalo. O alumínio é um exemplo de metal que, ainda que suficientemente solúvel em mercúrio $(0,002 \%)$, não pode ser determinado por VRA visto que o potencial onde ocorre sua oxidação é de cerca de $-1,7 \mathrm{~V} \cdot{ }^{16}$ As aplicações da VRA em águas naturais têm sido centradas principalmente nos metais $\mathrm{Cu}, \mathrm{Pb}, \mathrm{Cd}$ e $\mathrm{Zn}$, sendo o limite de detecção na ordem de $10^{-9}$ a $10^{-11} \mathrm{~mol} \mathrm{~L}^{-1} .^{17}$

\section{Voltametria de redissolução catódica não adsortiva (VRC)}

A VRC não adsortiva é utilizada principalmente na determinação de ânions orgânicos ou inorgânicos ( $\left.\mathrm{A}^{*}\right)$ pelo processo de formação de um sal de mercúrio pouco solúvel. A formação do sal mercuroso ocorre em duas etapas. Primeiramente, durante a aplicação de um potencial próximo de zero ou pouco negativo ocorre a oxidação do mercúrio metálico (3), seguido da formação e deposição do sal $\left(\mathrm{Hg}_{2} \mathrm{~A}_{2}\right)$ na superfície do eletrodo (4).

$$
\begin{gathered}
2 \mathrm{Hg} \rightarrow \mathrm{Hg}_{2}{ }^{2+}+2 \mathrm{e}^{-} \\
2 \mathrm{Hg}_{2}{ }^{2+}+2 \mathrm{~A}^{-} \rightarrow \mathrm{Hg}_{2} \mathrm{~A}_{2}
\end{gathered}
$$

Durante a varredura de potencial, o próprio mercúrio do sal formado é reduzido (5), produzindo uma corrente que é proporcional à concentração do ânion na amostra.

$$
\mathrm{Hg}_{2} \mathrm{~A}_{2}+2 \mathrm{e}^{-} \rightarrow 2 \mathrm{Hg}^{\mathrm{o}}+2 \mathrm{~A}^{-}
$$

A determinação de iodeto é um exemplo clássico da VRC com a formação de um sal mercuroso. ${ }^{18,19} \mathrm{O}$ limite de detecção do método utilizando 1 min de deposição é de $0,08 \mathrm{nmol} \mathrm{L}^{-1}$ para iodeto e de 0,2 $\mathrm{nmol} \mathrm{L} \mathrm{L}^{-1}$ para iodato, o que permitiu o estudo pioneiro da especiação química do iodo em águas de chuva. ${ }^{20}$

\section{Voltametria de redissolução catódica adsortiva (VRCAd)}

A adsorção de espécies orgânicas na gota de mercúrio na voltametria anódica foi por muitos anos vista apenas como uma interferência indesejada, que deveria ser eliminada empregando-se, por exemplo, métodos de oxidação por ultravioleta. ${ }^{21,22}$ Foi somente nos anos 80 que o uso das propriedades adsortivas de compostos orgânicos e de complexos organometálicos levou ao desenvolvimento da chamada 
voltametria de redissolução catódica adsortiva, dando início ao desenvolvimento de eletrodos quimicamente modificados. ${ }^{23}$

$\mathrm{Na}$ análise de metais por VRCAd, o metal é convertido em um complexo orgânico (ML) pela adição do ligante (L) em solução (6). Este complexo é adsorvido na gota de mercúrio em um potencial menos negativo que o potencial de pico.

$$
\mathrm{M}^{\mathrm{n}+}+\mathrm{L}^{\mathrm{m}-} \rightarrow \mathrm{ML}^{(\mathrm{n}-\mathrm{m})} \rightarrow \mathrm{ML}^{(\mathrm{n}-\mathrm{m})} \text { ads }
$$

A agitação da solução acelera o processo de pré-concentração, e após alguns segundos de repouso (10-30 s), a varredura de potencial no sentido mais negativo proporciona a redissolução de toda monocamada adsorvida. Existe a possibilidade do metal ser reduzido (7), ou de um grupo funcional do ligante orgânico ser reduzido (8).

$$
\begin{gathered}
\mathrm{ML}^{(\mathrm{n}-\mathrm{m})} \text { ads }+\mathrm{e}-\rightarrow \mathrm{M}^{(\mathrm{n}-1)}+\mathrm{L}^{\mathrm{m}-} \\
\mathrm{ML}^{(\mathrm{n}-\mathrm{m})} \text { ads }+\mathrm{e}-\rightarrow \mathrm{M}^{(\mathrm{n}+)}+\mathrm{L}^{(\mathrm{m}-1)}
\end{gathered}
$$

A análise de alumínio se tornou possível por VRCAd devido à complexação deste metal com o ligante ácido 1,2- di-hidroxiantraquinona-3- sulfônico (DASA), que por sua vez adsorve na gota de mercúrio em potenciais pouco negativos. Durante a varredura de potencial ocorre a redução do ligante em $-1,2 \mathrm{~V}$, sendo suficientemente afastado do potencial de redução da água. ${ }^{24} \mathrm{O}$ ligante 8-hidroxiquinolina (oxina) forma complexos com diversos metais e especialmente com cobre, chumbo e cádmio há uma grande sensibilidade analítica. A redução de cada um destes metais em diferentes potenciais torna possível sua análise simultânea. Atualmente, o limite de detecção de métodos que empregam a VRCAd é da ordem de subnanomolar, chegando até $4 \times 10^{-14} \mathrm{~mol} \mathrm{~L}^{-1}$ para a platina, utilizando $1 \mathrm{~min}$ de pré-concentração. ${ }^{25}$

\section{PARTE EXPERIMENTAL}

O sistema voltamétrico utilizado foi composto de potenciostato $\mu$ Autolab tipo III, sistema Metrohm 663 VA Stand com eletrodo de trabalho de mercúrio (gota $0,25 \mathrm{~mm}^{2}$ ), eletrodo de referência de $\mathrm{Ag}$ / $\mathrm{AgCl}\left(\mathrm{KCl} 3 \mathrm{~mol} \mathrm{~L}^{-1}\right)$ e eletrodo auxiliar de carbono vítreo e, interface Autolab IME (GPES), controlados por computador.

A solução de oxina (AnalaR) foi preparada na concentração de $0,10 \mathrm{~mol} \mathrm{~L}^{-1} \mathrm{em} \mathrm{HCl} 0,50 \mathrm{~mol} \mathrm{~L}^{-1}$ (Synth previamente purificado) ${ }^{26}$

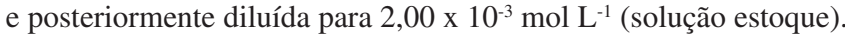
O tampão borato foi preparado com ácido bórico $\left(1,00 \mathrm{~mol} \mathrm{~L}^{-1}\right.$, Aristar-BDH) e $\mathrm{NH}_{3}\left(0,40 \mathrm{~mol} \mathrm{~L}^{-1}\right.$; Synth previamente purificada) para manter o $\mathrm{pH}$ em torno de 8,5. As soluções padrões de cobre e chumbo (de $1,00 \times 10^{-3}$ a $1,00 \times 10^{-6} \mathrm{~mol} \mathrm{~L}^{-1}$ ) foram preparadas a partir da solução padrão para absorção atômica $1 \mathrm{mg} \mathrm{mL}^{-1} \mathrm{em} 2 \%$ de $\mathrm{HNO}_{3}$ (Acros Organics).

A determinação de chumbo foi realizada por VRA ${ }^{16} \mathrm{em} 10 \mathrm{~mL}$ da solução ( $\mathrm{pH}$ ajustado para 4), utilizando tipicamente 1 min de pré-concentração em $-1,0 \mathrm{~V}$, varredura com pulso diferencial (25 $\mathrm{mV}), 5$ pulsos por s, velocidade de varredura de $20 \mathrm{mV} \mathrm{s}^{-1} \mathrm{e}$ faixa de potencial de varredura de $-0,50$ a $-0,25 \mathrm{~V}$.

As determinações de cobre foram realizadas utilizando a $\operatorname{VRCAd}^{27} \mathrm{em} 10 \mathrm{~mL}$ de solução, ligante oxina na concentração final de $20 \mu \mathrm{mol} \mathrm{L} \mathrm{L}^{-1}$ e tampão borato $0,01 \mathrm{~mol} \mathrm{~L}^{-1}$. Foi utilizado tipicamente 1 min de pré-concentração sob agitação em $-0,15 \mathrm{~V}$, as varreduras foram com pulso diferencial de altura de pulso de $50 \mathrm{mV}, 5$ pulsos por s, velocidade de $20 \mathrm{mV} \mathrm{s}^{-1}$ e faixa de potencial tipicamente entre $-0,35$ e - 0,65 V. Para ambos os métodos, a concentração do metal na amostra foi determinada após 3 adições de padrão.

Para armazenamento das amostras de água potável, foram utilizados frascos de polietileno de alta densidade de $100 \mathrm{~mL}$, previamente lavados com ácido nítrico e armazenados sem secar para evitar contaminação, de acordo com procedimento descrito por Campos e colaboradores. ${ }^{26}$ Toda manipulação e análise foram realizadas usando luvas plásticas descartáveis limpas. Após a coleta das amostras, estas foram armazenadas em geladeira, sendo analisadas dentro de 2 dias.

$\mathrm{O}$ procedimento de coleta das amostras de água variou de acordo com os objetivos propostos para cada série de experimentos e, portanto, será discutido juntamente com os resultados.

É importante enfatizar que em termos de saúde pública, sugerese o volume de $1 \mathrm{~L}$ de água para o monitoramento da concentração de metais. ${ }^{28}$ No entanto, neste trabalho, optou-se por coletar apenas 100 mL de água logo pela manhã porque no caso da preparação de mamadeiras, por exemplo, 100-200 mL pode ser todo o volume utilizado. Outro motivo de amostrar um pequeno volume foi o fato de que um maior volume de água implica na possível diluição das espécies de interesse pelo processo de 'lavagem' do encanamento, dificultando as análises dos metais.

\section{RESULTADOS}

\section{Branco de reagentes, faixa linear de trabalho e exemplo}

A concentração média de cobre para 4 determinações do branco de reagentes foi de $0,77 \pm 0,13 \mathrm{nmol} \mathrm{L}^{-1}$, e para o chumbo foi inferior ao limite de detecção, que é de $0,27 \mathrm{nmol} \mathrm{L}^{-1}$, utilizando 5 min de pré-concentração. A faixa linear do método está principalmente relacionada com o tamanho da gota empregada, isto é, quanto maior a gota, maior será a área disponível e a corrente gerada. No caso da voltametria anódica a faixa linear de trabalho é extensa, pois conta com todo o volume da gota para formação do amálgama. Porém, no caso da voltametria catódica adsortiva, a gota de mercúrio é recoberta com uma monocamada e, portanto, pode atingir mais facilmente a saturação.

Utilizando um tempo de pré-concentração de 1 min, a faixa linear de trabalho para cobre por VRCAd chegou a aproximadamente $30 \mathrm{nA}$ de corrente, que é equivalente a $110 \mathrm{nmol} \mathrm{L}^{-1}$ de cobre. A equação da reta oriunda da curva analítica foi: corrente $(\mathrm{nA})=0,40+0,28\left[\mathrm{Cu}^{2+}\right]$ (nmol L-1), com um coeficiente de correlação linear (r) de 0,9981. É importante lembrar que a faixa linear de trabalho deve ser observada pela corrente gerada e não pela concentração do metal, pois quanto maior o tempo de pré-concentração, mais baixa é a concentração de metal que satura o eletrodo. A estreita faixa de trabalho para o cobre levou à necessidade de se diluir a amostra de água da torneira em pelo menos 10 vezes antes da análise por VRCAd.

A Figura 1 apresenta os voltamogramas correspondentes à determinação de cobre e de chumbo em uma amostra de água de torneira. Para determinação de cobre foi preciso diluir a amostra 8 vezes e utilizar apenas $30 \mathrm{~s}$ de pré-concentração para assegurar que até a última adição de padrão, a corrente gerada estaria dentro da faixa linear de trabalho. As concentrações encontradas foram de $11,4 \mathrm{nmol} \mathrm{L}{ }^{-1}$ de cobre (na alíquota diluída) e de 4,70 nmol L-1 de chumbo.

\section{Interferência no sinal voltamétrico}

Na determinação de cobre, a sensibilidade (inclinação da curva analítica) da VRCAd é cerca de 5 vezes maior do que a VRA. Isso porque na VRCAd, há redissolução completa de todo o filme organometálico, enquanto que na VRA o metal é difundido em direção ao interior da gota de mercúrio, e durante a varredura de potencial apenas parte do metal depositado é reoxidado. ${ }^{16}$ Uma maneira de minimizar a interferência de picos adjacentes na VRCAd e elevar ainda mais a sensibilidade do método, é realizar uma deposição em potencial bastante negativo antes de fazer a varredura catódica (neste caso, do potencial menos negativo para mais negativo). ${ }^{29}$ 

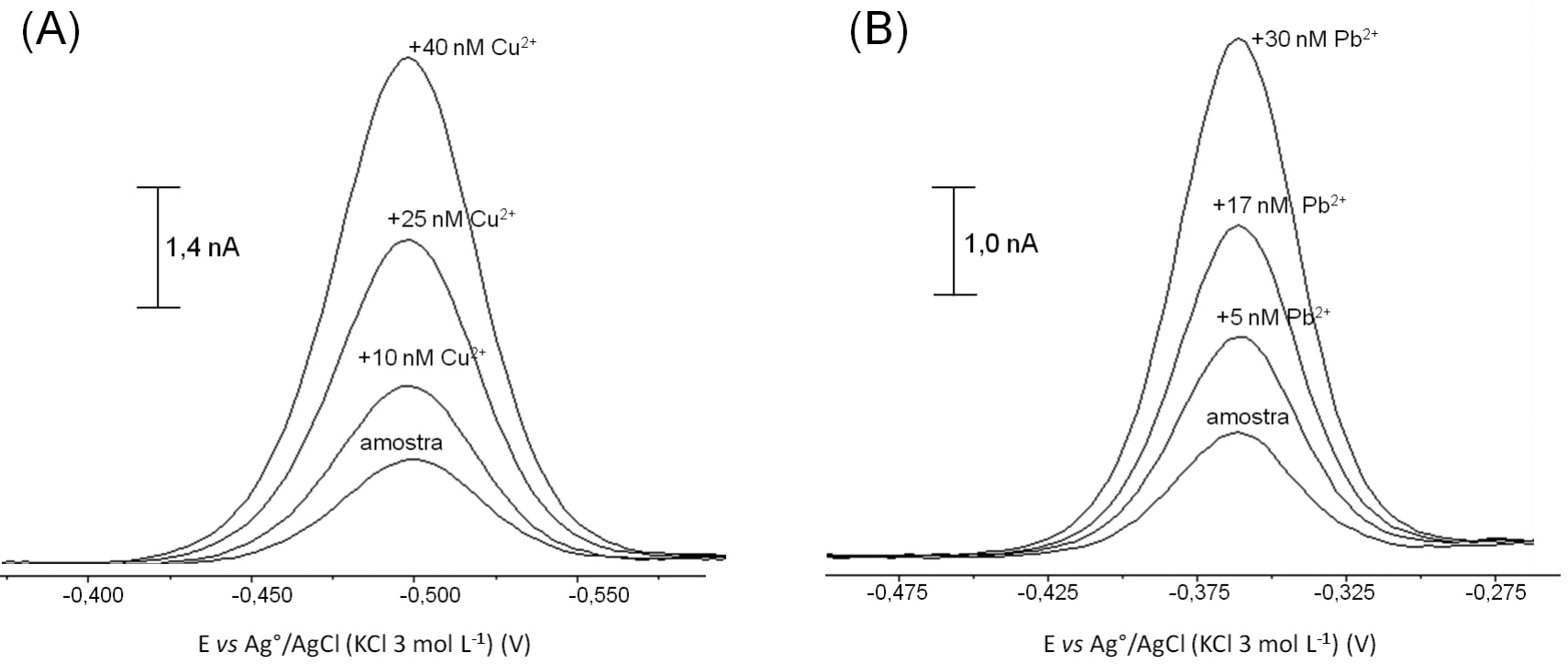

Figura 1. Voltamogramas de pulso diferencial. (A) Determinação de cobre por VRCAd para uma alíquota de água de torneira diluída 8 vezes, contendo 11,4 nmol $L^{-1} \mathrm{Cu}$. Utilizou-se oxina $\left(20,0 \mu \mathrm{mol} \mathrm{L}^{-1}\right)$ e tampão borato $\left(0,01 \mathrm{~mol} \mathrm{~L}^{-1}\right)$. A pré-concentração foi em -0,25 V $(30 \mathrm{~s})$, com pulsos de $50 \mathrm{mV}, 5$ pulsos $\mathrm{s}^{-1}$ e velocidade varredura de $20 \mathrm{mV} \mathrm{s}^{-1}$. (B) Determinação de chumbo em amostra de água de torneira por VRA contendo 4,7 nmol $L^{-1}$ Pb. A pré-concentração foi em -1,0 V (1 min), com pulsos de $25 \mathrm{mV}$, 5 pulsos $\mathrm{s}^{-1}$ e velocidade de varredura de $20 \mathrm{mV} \mathrm{s} \mathrm{s}^{-1}$

A Figura 2 compara os voltamogramas obtidos utilizando dois tipos de pré-concentração sob agitação para determinação de cobre por VRCAd. No caso da pré-concentração em - 0,15 V por 1 min (Figura 2 varredura - a), tem-se apenas o fenômeno de adsorção do complexo $\mathrm{Cu}$-oxina, seguido de $15 \mathrm{~s}$ de repouso e varredura catódica. Quando a pré-concentração é realizada em -1,0 V (Figura 2 varredura - b), tem-se inicialmente a formação de amálgama com o cobre. Após $10 \mathrm{~s}$ de repouso em $-1,0 \mathrm{~V}$ foi feito um salto de potencial para $-0,15 \mathrm{~V}$, mantendo o repouso por mais $15 \mathrm{~s}$ antes da varredura. Nesse período de $15 \mathrm{~s}$, o metal é redissolvido (oxidado), complexado pela oxina e adsorvido na gota de mercúrio. Esta combinação de formação de amálgama com varredura catódica funciona como uma dupla pré-concentração: a primeira, pré-concentra o metal diretamente na gota de mercúrio e a segunda, muito próximo da gota, por causa da redissolução do metal que complexa com o ligante e retorna para a gota na forma de uma monocamada adsorvida. Esse salto de potencial levou ao ganho de sensibilidade para o cobre em cerca de 4 vezes (Figura 2 a e b). $\mathrm{O}$ salto de potencial antes da varredura também melhora a definição de picos adjacentes, como pode ocorrer com cobre e chumbo, quando presentes em concentrações equivalentes. A varredura c da Figura 2 foi realizada após pré-concentração e varredura a partir de $-0,15 \mathrm{~V}$, mostrando a presença de um ombro adjacente ao pico do cobre. Já na varredura d, os picos estão bem separados graças à pré-concentração em $-1,0 \mathrm{~V}$ antes da varredura catódica (iniciando em $-0,15 \mathrm{~V}$ ).

\section{Estudo da lixiviação de chumbo pela água}

No processo de tratamento da água é comum o uso de sais de hipoclorito, como $\mathrm{NaOCl}$, para desinfecção, além do ácido fluorsilícico $\left(\mathrm{H}_{2} \mathrm{SiF}_{6}\right)$ no processo de fluoretação, resultando numa água com $\mathrm{pH}$ abaixo de 7. $\mathrm{O}$ aumento da acidez da água pode promover, por exemplo, a solubilização do $\mathrm{PbO}_{2}$, um produto comum de corrosão de encanamentos à base de chumbo. ${ }^{30}$

Outro fator agravante na contaminação por metais deve-se ao

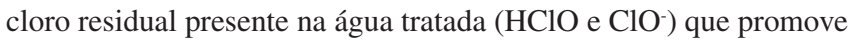
a dissolução de metais presentes nos encanamentos, pois as reações redox envolvendo o ácido hipocloroso são favorecidas em meio ácido $\left(2 \mathrm{HClO}+2 \mathrm{H}^{+}+2 \mathrm{e}^{-} \rightarrow \mathrm{Cl}_{2}+2 \mathrm{H}_{2} \mathrm{O} ; \mathrm{E}^{0}=+1,63 \mathrm{~V}\right)$. Assim, metais

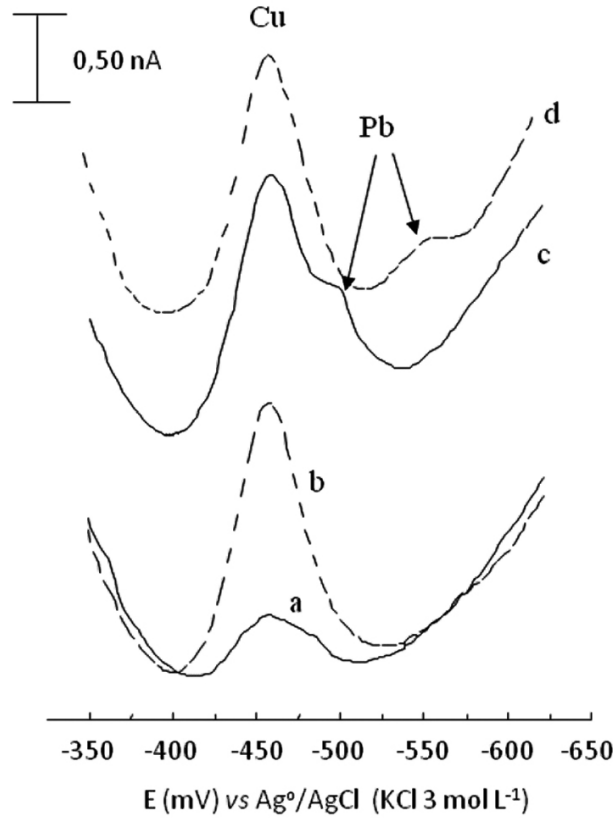

Figura 2. Voltamogramas de pulso diferencial obtidos para uma solução de água suprapura contendo 4,60 $\mathrm{nmol} \mathrm{L}^{-1} \mathrm{Cu}$, oxina $\left(20,0 \mu \mathrm{mol} \mathrm{L} \mathrm{L}^{-1}\right)$ e tampão borato $\left(0,01 \mathrm{~mol} \mathrm{~L}^{-1}\right)$ : a) pré-concentração $(1 \mathrm{~min})$ e varredura iniciada em $-0,15 \mathrm{~V}$; b) pré-concentração (1 min) em -1,0 V e varredura iniciada em -0,15 $V$; c) condições descritas em ' $a$ ' com adição de 3,0 nmol $\mathrm{L}^{-1} \mathrm{~Pb}$; d) condições descritas em ' $b$ ' com adição de 3,0 nmol $L^{-1} \mathrm{~Pb}$. A janela de varredura mostrada foi restrita ao intervalo de interesse. A altura de pulso foi de $50 \mathrm{mV}, 5$ pulsos $\mathrm{s}^{-1}$ e velocidade de varredura de $20 \mathrm{mV} \mathrm{s}^{-1}$

como ferro $\left(\mathrm{E}^{0} \mathrm{Fe}^{3+} / \mathrm{Fe}=-0,04 \mathrm{~V}\right)$, cobre $\left(\mathrm{E}^{0} \mathrm{Cu}^{2+} / \mathrm{Cu}=+0,34 \mathrm{~V}\right)$ e chumbo $\left(\mathrm{E}^{0} \mathrm{~Pb}^{2+} / \mathrm{Pb}=-0,13 \mathrm{~V}\right)$ podem ser facilmente oxidados pelo ácido hipocloroso se presentes na rede de abastecimento de água da cidade. $\mathrm{O}$ fluorsilicato de chumbo $\left(\mathrm{PbSiF}_{6}\right)$ que é depositado nas paredes do cano é relativamente solúvel e, portanto, sensível às alterações da acidez da água. ${ }^{31}$

Foi realizado um experimento para avaliar a importância do tempo de estagnação da água em canos de chumbo, assim como sua 
(A)

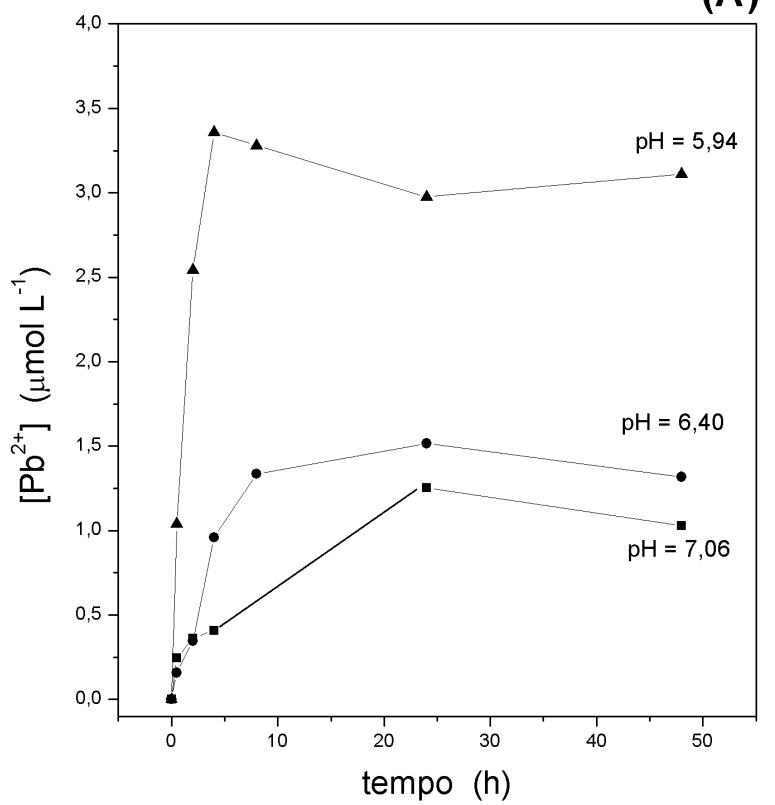

(B)

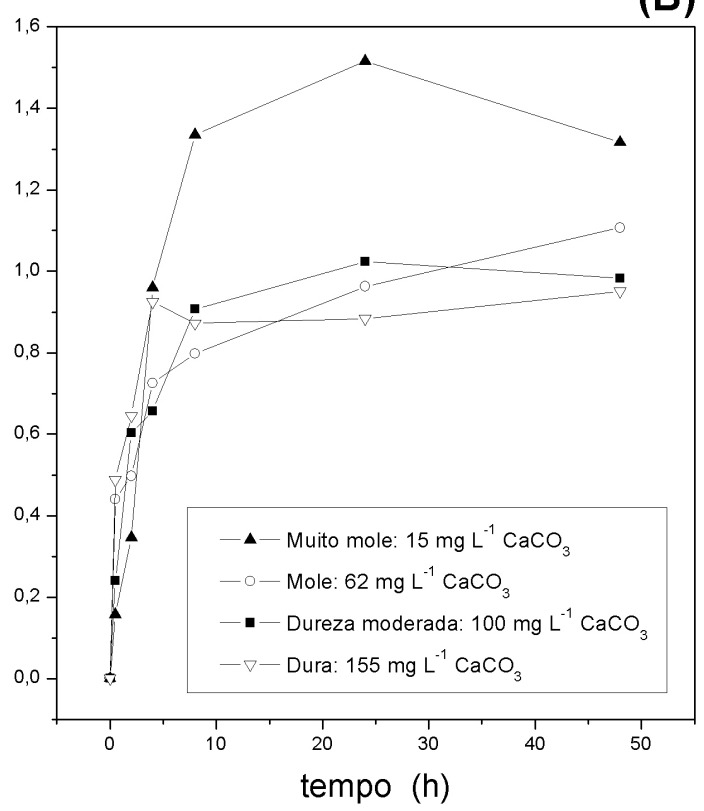

Figura 3. Lixiviação de chumbo com o tempo de estagnação da água no cano de chumbo, de acordo com a variação de pH (A) e dureza (B). Note que a concentração de chumbo é da ordem de $\mu \mathrm{mol} \mathrm{L}^{-1}$ por haver um elevado grau de contaminação pelo cano de chumbo

correlação com o pH e dureza da água. Para esse estudo, foi utilizado um cano à base de chumbo de $14,5 \mathrm{~cm}$ de altura e $3,5 \mathrm{~cm}$ de diâmetro, proveniente de uma casa demolida, e adquirido no comércio de sucata. O interior do cano foi lavado com escova para remoção de possíveis depósitos minerais. Uma das laterais do cano foi vedada com uma peça de teflon e um anel de borracha, permitindo seu posicionamento na vertical e a adição de $110 \mathrm{~mL}$ de água para o experimento.

A concentração de chumbo na água foi medida sempre em triplicata, tanto antes de ser introduzida no cano, como após diversos intervalos de tempo. Antes de cada análise a amostra era homogeneizada, sendo retirados um volume de $100 \mu \mathrm{L}$ e diluídos para 10 $\mathrm{mL}$. Tanto para o $\mathrm{pH}$ original da água $(6,40)$ como para os outros dois valores (ajustados com $\mathrm{HCl}$ e $\mathrm{NH}_{3}$ ), o processo de lixiviação de chumbo com o tempo foi evidente. Apenas $30 \mathrm{~min}$ de residência da água no cano foram suficientes para elevar a concentração do metal acima do limite tolerável de $48,3 \mathrm{nmol} \mathrm{L}^{-1}$, para os três valores de pH estudados (Figura $3 \mathrm{~A}$ ).

Um incremento relativamente pequeno na acidez da água $(\mathrm{pH}$ 5,94 ) levou a uma capacidade de lixiviação de chumbo 3 vezes maior, enquanto que a diminuição da acidez $(\mathrm{pH} 7,06)$ provocou uma desaceleração desse processo. Após cerca de $8 \mathrm{~h}$ de contato com a água estagnada, foi atingido um patamar no processo de oxidação (dissolução) do chumbo, que pode ter ocorrido devido ao esgotamento de espécies oxidantes contendo cloro, consumidas no processo de oxidação do metal.

Com o passar dos anos, carbonatos de óxidos depositados nas paredes do cano podem causar sua passivação e dificultar o processo de lixiviação do metal. ${ }^{32}$ A capacidade de passivação está correlacionada à dureza da água, que é definida como a concentração total de íons alcalino-terrosos. Devido à abundância de cálcio e magnésio, a dureza pode ser expressa em termos da concentração desses dois elementos. A unidade utilizada é em $\mathrm{mg}$ de $\mathrm{CaCO}_{3}$ por $\mathrm{L}$ de água, sendo calculada de acordo com a relação: dureza $=2,50\left(\mathrm{Ca}^{2+} \mathrm{mg}\right.$ $\left.\mathrm{L}^{-1}\right)+4,12\left(\mathrm{Mg}^{2+} \mathrm{mg} \mathrm{L}^{-1}\right)$.

A fim de avaliar o efeito da dureza da água na capacidade de lixiviação de chumbo, foram adicionados $\mathrm{CaCl}_{2}$ e $\mathrm{Na}_{2} \mathrm{CO}_{3}$ para elevar a dureza da água da torneira, que era originalmente de $14,7 \mathrm{mg} \mathrm{L}^{-1}$ $\mathrm{CaCO}_{3}$ (muito mole)..$^{33}$ Os valores de $\mathrm{pH}$ resultantes foram de: 7,54 para a concentração final de $62,0 \mathrm{mg} \mathrm{L}^{-1} \mathrm{CaCO}_{3}$ (água mole); $\mathrm{pH} 8,27$ para 99,6 mg L-1 $\mathrm{CaCO}_{3}$ (dureza moderada) e $\mathrm{pH} 8,86$ para $155 \mathrm{mg} \mathrm{L}^{-1}$ $\mathrm{CaCO}_{3}$ (água dura). Para as 3 durezas estudadas, os perfis de oxidação do chumbo foram muito próximos, atingindo um patamar em torno de $0,9 \mu \mathrm{mol} \mathrm{L}^{-1}$ após $8 \mathrm{~h}$ de experimento (Figura 3B). Esse comportamento foi similar àquele observado para a água com apenas o $\mathrm{pH}$ ajustado para 7,06. É possível que o tempo de residência da água, durante o experimento, não tenha sido suficiente para passivar as paredes do cano sendo que, neste caso, o processo de lixiviação pode ter sido determinado pela acidez da água e presença de espécies oxidantes.

\section{Escoamento da água da torneira}

Tendo em vista a importância do tempo de estagnação da água no processo de lixiviação de metais, foi realizado um estudo para verificar a importância de se deixar a água escoar antes de utilizá-la para ingestão direta ou preparação de alimentos. Alíquotas de apenas 100 $\mathrm{mL}$ foram coletadas na torneira de entrada da casa. A primeira delas, logo pela manhã, com pelo menos $8 \mathrm{~h}$ sem qualquer uso doméstico, e outras duas coletadas após escoamento.

A Figura 4 mostra que com $3 \mathrm{~L}$ de escoamento, a concentração de cobre teve uma queda de cerca de $70 \%$, e para o chumbo de aproximadamente $50 \%$. Após esse volume, a concentração dos metais baixou menos abruptamente. Estes resultados demonstram que um volume de água escoada relativamente pequeno pode reduzir significativamente as concentrações dos metais na água. Além disso, a água escoada pode ser aproveitada para outros fins domésticos.

Deve-se ressaltar que embora as concentrações de metais na primeira alíquota tenham sido mais elevadas que as demais, todas estiveram abaixo da concentração tolerada pela legislação brasileira de $31,5 \mu \mathrm{mol} \mathrm{L}^{-1}\left(2 \mathrm{mg} \mathrm{L}^{-1}\right)$ para cobre e de $48,3 \mathrm{nmol} \mathrm{L}^{-1}\left(10 \mu \mathrm{g} \mathrm{L}^{-1}\right)$ para o chumbo.

Esse tipo de experimento, além de muito simples, pode ser de grande importância em termos sociais, pois uma vez identificada a presença de elevadas concentrações de metais na água de casas antigas, os moradores podem ser orientados para escoar a água em um balde antes de utilizá-la para ingestão ou preparação de alimentos, após longos períodos de estagnação. 


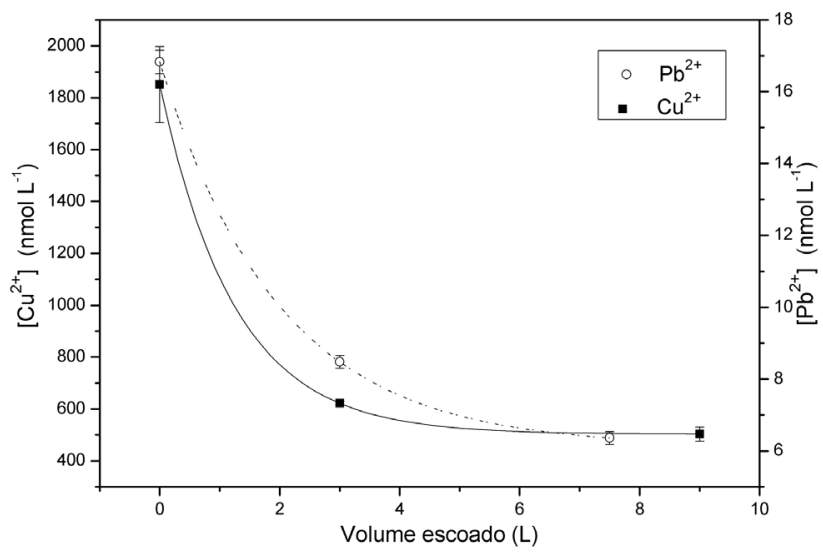

Figura 4. Concentração média de cobre e chumbo e desvio padrão $(n=3)$ de acordo com o volume de água escoada da torneira da entrada da residência do bairro Campos Elíseos

\section{Variabilidade na concentração de $\mathrm{Cu}$ e $\mathrm{Pb}$ na água de abastecimento}

Outro ponto de interesse foi avaliar se a água de abastecimento público teria importantes variações nas concentrações de metais no ponto de entrada da casa em dias distintos. Nesse experimento, as concentrações de cobre e chumbo foram avaliadas em uma alíquota de $100 \mathrm{~mL}$ coletada na água da torneira de entrada de uma das casas, também pela manhã, antes de qualquer uso doméstico, sendo que os dias foram numerados a partir da primeira coleta (Tabela 1). Para possibilitar a análise de cobre por VRCAd, as amostras foram diluídas tipicamente em 100 vezes, o que pode ter contribuído para elevar a imprecisão das análises.

Tabela 1. Concentrações médias e desvios padrões de cobre e chumbo em amostras de água da torneira coletadas na entrada da casa dos Campos Elíseos. As concentrações relatadas para cada dia se referem à média de 3 análises, enquanto a média geral trata da média dos dias amostrados

\begin{tabular}{ccc}
\hline Dia & {$\left[\mathrm{Cu}^{2+}\right]\left(\mathrm{nmol} \mathrm{L}^{-1}\right)$} & {$\left[\mathrm{Pb}^{2+}\right]\left(\mathrm{nmol} \mathrm{L}^{-1}\right)$} \\
\hline 1 & $999 \pm 69(7 \%)$ & - \\
2 & $1.652 \pm 283(17 \%)$ & $19,7 \pm 0,4(2,0 \%)$ \\
4 & $1.371 \pm 140(10 \%)$ & $16,7 \pm 0,3(1,7 \%)$ \\
7 & $1.550 \pm 39(2 \%)$ & $15,0 \pm 0,3(1,9 \%)$ \\
10 & $1.857 \pm 252(14 \%)$ & $16,8 \pm 0,3(1,7 \%)$ \\
média geral & $1.486 \pm 324(22 \%)$ & $17 \pm 2(11 \%)$ \\
\hline
\end{tabular}

A concentração de cobre variou em até quase $100 \%$ entre os dias 1 e 10 , porém, a variação dos valores médios foi de $22 \%$. Para ambos os metais, houve maior variação na concentração entre os dias de amostragem do que na precisão das análises.

As variações na concentração dos metais podem ter ocorrido por diversos motivos. Um deles seria o tempo de residência da água no encanamento durante o período noturno, que pode ser variável de acordo com a demanda. Pequenas variações na adição de cloro na água durante o tratamento também poderiam levar a alterações no $\mathrm{pH}$ e, consequentemente, no poder de lixiviação de metais. Outro fato é que o reservatório que abastece uma mesma residência pode ser alterado de acordo com a demanda ou em caso de manutenção do poço, alterando o percurso percorrido pela água até o consumidor final.

\section{Concentração de $\mathrm{Cu}$ e $\mathrm{Pb}$ em água potável}

A cidade de Ribeirão Preto é totalmente abastecida por água subterrânea, sendo esta classificada como 'classe especial' e, portanto, seu tratamento consiste apenas na cloração e fluoretação antes da distribuição. Em um dos poços municipais, uma amostra de $1 \mathrm{~L}$ de água tratada foi coletada após deixar-se escoar 2 L para obtenção da concentração típica dos metais antes da sua distribuição. As coletas de água de torneira foram realizadas em dois bairros centenários, que fazem parte da zona central da cidade (Campos Elíseos e Vila Tibério), e outro bairro relativamente recente ( $\sim 30$ anos; Jardim Recreio). A primeira alíquota de $100 \mathrm{~mL}$ da manhã foi coletada primeiramente na torneira de entrada da água na casa junto ao registro (denominada «quintal〉) e depois na pia da cozinha, na torneira ligada ao reservatório da residência. Na residência do Jardim Recreio, uma alíquota de água foi retirada da torneira ligada à tubulação que passa pelo sistema de aquecimento solar.

O primeiro ponto a destacar é que as concentrações de cobre e chumbo obtidas para todas as amostras estudadas estiveram dentro do padrão aceitável para água potável (Tabela 2).

Tabela 2. Concentração média de cobre $(n=2)$ e chumbo $(n=3)$, desvio padrão e desvio padrão relativo em amostras de água de consumo de residências e em poços de abastecimento da cidade após* o tratamento químico e antes** do tratamento

\begin{tabular}{llcc}
\hline bairro & amostra & {$\left[\mathrm{Cu}^{2+}\right]\left(\mathrm{nmol} \mathrm{L}^{-1}\right)$} & {$\left[\mathrm{Pb}^{2+}\right](\mathrm{nmol} \mathrm{L}$} \\
\hline \multirow{2}{*}{ Jardim Recreio } & quintal & $479 \pm 31(7 \%)$ & $3,85 \pm 0,3(8 \%)$ \\
& cozinha & $3.200 \pm 130(4 \%)$ & $7,55 \pm 0,3(4 \%)$ \\
& aquecedor & $4.550 \pm 710(16 \%)$ & $6,65 \pm 0,3(5 \%)$ \\
\hline Campos & quintal & $995 \pm 74(7 \%)$ & $15,0 \pm 0,3(2 \%)$ \\
Elíseos & cozinha & $2.270 \pm 130(6 \%)$ & $30,6 \pm 0,1(0,3 \%)$ \\
\hline Vila Tibério & quintal & $302 \pm 37(12 \%)$ & $8,64 \pm 0,3(3 \%)$ \\
& cozinha & $283 \pm 50(18 \%)$ & $2,76 \pm 0,1(4 \%)$ \\
& poço municipal* & $147 \pm 11(7 \%)$ & $0,31 \pm 0,1(32 \%)$ \\
& poço municipal** & & $0,43 \pm 0,2(47 \%)$ \\
\hline Vários bairros & 11 poços & $34,1 \pm 50(147 \%)$ & $0,77 \pm 0,5(65 \%)$ \\
& municipais* & & \\
\hline & & & \\
\hline
\end{tabular}

As concentrações dos metais foram muito inferiores na água do reservatório municipal em comparação com as das casas. Essa baixa concentração de metais se repetiu em outros 10 poços municipais estudados (Tabela 2) e, portanto, é possível inferir que há uma importante contaminação dos metais durante o percurso da água desde sua fonte até a entrada das casas. As concentrações de chumbo na água antes e após o tratamento químico não foram significativamente diferentes (teste $\mathrm{t}, \mathrm{P}=0,05$ ).

Além da contaminação pública, a tubulação interna da própria residência, seus reservatórios e até mesmo as torneiras metálicas podem ser relevantes fontes de cobre e chumbo no interior da casa. A água que passou pelo sistema de aquecimento na residência do Jardim Recreio apresentou aproximadamente 10 vezes mais cobre que a água do quintal, devido à presença de cobre na liga metálica das placas de aquecimento.

A menor contaminação da água ocorreu na casa da Vila Tibério, que está localizada a cerca de $200 \mathrm{~m}$ do poço municipal monitorado neste trabalho. Nessa casa, as concentrações de cobre na água do quintal e da cozinha não foram diferentes (teste $t ; P>0,05$ ), enquanto que a concentração de chumbo foi maior na água do quintal, sugerindo que o próprio material da torneira pode ter sido a fonte dominante de chumbo.

\section{CONCLUSÕES}

Neste trabalho, foi possível identificar que houve uma contaminação relevante de cobre e chumbo na água de Ribeirão Preto durante sua distribuição, porém, mantendo-se dentro dos níveis aceitos pela 
legislação. Incrementos relativamente pequenos na acidez rapidamente elevaram a corrosão de encanamentos à base de chumbo. No entanto, o aumento da dureza da água não pareceu ter efeito durante o tempo do experimento, sugerindo que os processos de deposição de óxidos e carbonatos ocorrem num período de tempo mais longo.

$\mathrm{O}$ escoamento de apenas $3 \mathrm{~L}$ de água reduziu consideravelmente as concentrações de cobre e chumbo, uma vez que tal contaminação não era na fonte. $\mathrm{O}$ escoamento, ainda que paliativo, pode ser sugerido aos moradores com problemas de contaminação excessiva da água. No caso da contaminação da água por chumbo presente em encanamentos ser um caso de saúde pública, as autoridades locais podem avaliar a viabilidade de elevar o $\mathrm{pH}$ da água no seu tratamento, a fim de minimizar seus efeitos.

Apesar da aplicação da voltametria de redissolução neste trabalho estar centrada na análise de cobre e chumbo em amostras de água potável, a abordagem teórica e experimental apresentada traz subsídios para uma gama de aplicações, que podem ser trabalhadas pelos alunos de graduação, seja em experimentos programados pelo professor, em disciplinas com apresentação de projetos, ou em monografias. Dado o elevado custo de um espectrômetro de absorção atômica com atomização eletrotérmica, muitas instituições podem optar por trabalhar com técnicas voltamétricas para análise de metais traços.

Para novo estudo de caso seria desejável amostrar a água de casas construídas até os anos de 1970, pois era comum utilizar canos de ferro galvanizado contendo grandes concentrações de impurezas de chumbo, ou até mesmo canos à base de chumbo. Outra sugestão é a coleta de pequenos volumes de água em bebedouros de escolas, pois as crianças, quando contaminadas, podem ter sequelas irreversíveis.

O trabalho aqui apresentado permitiu ilustrar um estudo de caso de grande relevância, que, além de poder levar à construção participativa do ensinar, pode também melhorar nosso conhecimento sobre a contaminação por metais traços na água de diferentes partes do Brasil.

\section{AGRADECIMENTOS}

Ao CNPq pelo financiamento (577010/2008-5), ao CNPq e CAPES pelas bolsas concedidas e à $\mathrm{C}$. $\mathrm{H}$. Coelho pelo valioso auxílio no início deste trabalho.

\section{REFERENCIAS}

1. Needleman, H. L.; Bellinger,; D.; Annu. Rev. Publ. Health 1991, 12, 111.

2. Needleman, H. L.; Gunnoe, C.; Leviton, A.; Reed, R., Peresie, H.; Maher, C.; Barrett, P.; New Engl. J. Med. 1979, 300, 689.

3. Warren, C.; Brush with Death: a social history of lead poisoning, $1^{\text {st }} \mathrm{ed}$., The Johns Hopkins University Press: Baltimore, 2000.

4. De Capitani, E. M.; Paoliello, M. M. B.; Almeida, G. R. C.; Rev. Med. (Rib. Preto) 2009, 42, 311.

5. Lytle, D. A.; Schock, M. R.; Journal-American Water Works Association $\mathbf{2 0 0 5}, 97,102$.

6. CDC - Center for Disease Control of the United States; Minutes of advisory committee on childhood lead poisoning prevention; http://www. cdc.gov/nceh/lead/ACCLPP/Meetings/Minutes/2004MarMinutes.pdf, acessada em Agosto 2012.
7. USEPA - United States Environmental Protection Agency; Elevated Lead in D.C. Drinking Water - A Study of Potential Causative Events, Final Summary Report. EPA 815-R-07-021; http://water.epa.gov/ lawsregs/rulesregs/sdwa/lcr/upload/2007_09_12_lcrmr_pdfs_report_ lcmr_elevatedleadindc_final_factsheet.pdf, acessada em Agosto 2012.

8. Coplan, M. J.; Patch, S. C.; Masters, R. D.; Bachman, M. S.; Neurotoxicology 2007, 28, 1032.

9. Alloway, B. J.; Ayres D. C.; Chemical Principles of Environmental Pollution, $1^{\text {st }}$ ed., Blackie Academic and Professional: Glasgow, 1994.

10. Lansdown, R.; Yule, W.; Lead Toxicity, History and Environmental Impact, The Johns Hopkins University Press: Baltimore, 1986.

11. Almeida, G. R. C.; Guerra, C. S.; Tanus-Santos, J. E.; Barbosa, F.; Gerlach, R. F.; Environ. Res. 2008, 107, 264.

12. Almeida, G. R. C.; Freitas, C. U.; Barbosa, F.; Tanus-Santos, J. E.; Gerlach, R. F.; Sci. Total Environ. 2009, 407, 1547.

13. Almeida, G. R. C.; Saraiva, M. C. P.; Barbosa, F.; Krug, F. J. Jr.; Cury, J. A.; Sousa, M. L. R.; Buzalaf, M. A. R.; Gerlach, R. F.; Environ. Res. 2007, 104, 337.

14. Sá, L. P.; Queiroz, S. L.; Quim. Nova 2007, 30, 2035.

15. Holler, F. J.; Skoog, D. A.; Crouch, S. R.; Princípios de Análise Instrumental, 6 ed., Bookman: Porto Alegre, 2009.

16. van den Berg, C. M. G. Em Chemical Oceanography; Riley, J. P., ed.; Academic Press: Londres, 1989, chap. 51.

17. Achterberg, E. P.; Braungardt, C.; Anal. Chim. Acta 1999, 400, 381.

18. Luther III, G. W.; Swartz, C. B.; Ullman, W. J.; Anal. Chem. 1988, 60, 1721 .

19. Campos, M. L. A. M.; Mar. Chem. 1997, 57, 107.

20. Campos, M. L. A. M.; Nightingale, P. D.; Jickells, T. D.; Tellus 1996, $48,106$.

21. Cavicchioli, A.; Gutz, I. G. R.; Quim. Nova 2003, 26, 913.

22. Campos, M. L. A. M.; Mello, L. C.; Zanette, D. R.; Sierra, M. M.; Bendo, A.; Quim. Nova 2001, 24, 257.

23. Fogg, A. G.; Anal. Proc. 1994, 31, 313.

24. van den Berg, C. M. G.; Anal. Chim. Acta 1991, 250, 265.

25. van den Berg, C. M. G.; Jacinto, G. S.; Anal. Chim. Acta 1988, 211, 129.

26. Campos, M. L. A. M.; Bendo, A.; Viel, F. C.; Quim. Nova 2002, 25, 808.

27. van den Berg, C. M. G.; J. Electroanal. Chem. 1986, 215, 111.

28. Edwards, M.; Triantafyllidou, S.; Best, D.; Environ. Sci. Technol. 2009, 43, 1618.

29. Campos, M. L. A. M.; van den Berg, C. M. G.; Anal. Chim. Acta 1994, $284,481$.

30. Xie, Y.; Wang, Y.; Singhal, V.; Giammar, D. E.; Environ. Sci. Technol. 2010, 44, 1093

31. Maas, R. P.; Patch, S. C.; Christian, A. M.; Coplan, M. J.; Neurotoxicology 2007, 28, 1023.

32. USEPA - United States Environmental Protection Agency; Actions You Can Take To Reduce Lead In Drinking Water. EPA 810-F-93-001; http:// water.epa.gov/drink/info/lead/lead1.cfm, acessada em Agosto 2012.

33. WQA-EUA - Water Quality Association of the United States of America; The WQA Glossary of Terms: H - Hardness; http://www.wqa.org/glossary.cfm?gl=626, acessada em Agosto 2012. 